\title{
International Journal of Technology
}

http://ijtech.eng.ui.ac.id

\section{Curing Characteristics and Physical Properties of Natural Rubber Composites Using Modified Clay Filler}

\author{
Abu Hasan ${ }^{1 *}$, Martha Aznury${ }^{1}$, Indah Purnamasari1 ${ }^{1}$ Maykel Manawan², Chandra Liza ${ }^{3}$ \\ ${ }^{1}$ Department of Chemical Engineering, Politeknik Negeri Sriwijaya, Jl. Srijaya Negara Bukit Besar \\ Palembang 30139, Indonesia \\ ${ }^{2}$ Department of Mechanical Engineering, Politeknik Negeri Jakarta, Jl. Margonda Raya, Depok 16424, \\ Indonesia \\ ${ }^{3}$ Center for Polymer Technology, Agency for the Assessment and Application Technology (BPPT), Puspiptek \\ Office area, Building 460, Serpong, Banten 15311, Indonesia
}

\begin{abstract}
The differences in the curing characteristics and physical properties of natural rubber samples using clay and modified clay as fillers were studied. After the clay was modified with dodecylamine, the rubber milling process was conducted at a temperature of $65-70^{\circ} \mathrm{C}$ to obtain the natural rubber compound. The content of clay and modified clay in the natural rubber was approximately $15 \mathrm{phr}$. A curing test at $150^{\circ} \mathrm{C}$ was performed, and then the physical properties were tested. The results of the physical properties test showed a significant increase in the tensile strength, from 16.3 to $25 \mathrm{MPa}$, a change in hardness from 43 to 54 Shore $\mathrm{A}$, a change in modulus of $300 \%$ from 1.6 to $4.6 \mathrm{MPa}$, a change in tear strength from 29.3 to $40.2 \mathrm{kN} / \mathrm{m}$, and a change in compression set from $25.75 \%$ to $30.57 \%$ due to the use of modified clay compared to the sample with unmodified clay. However, some physical properties-such as elongation at break, from $720 \%$ to $600 \%$-decreased dramatically. $S_{\max }$ increased sharply, from 7.05 to $11.45 \mathrm{~kg}$-cm, while optimum cure and scorch time decreased sharply, from 11.23 to 6.43 minutes and from 6.35 to 2.38 minutes, respectively. FTIR and XRD analyses showed evidence of clay modification. Similarly, the AFM and SEM analyses of clay surfaces and the dispersion of the clay in the rubber showed that the dispersion of the modified clay in the rubber was better than that of unmodified clay. The TA/DTA analysis also supported the above explanation, particularly for the changes in curing characteristics and physical properties.
\end{abstract}

Keywords: Clay; Dodecylamine; Modified clay; Natural rubber; Reinforcement

\section{Introduction}

Global warming has become an increasingly serious problem in recent years, motivating a strong worldwide effort to address its causes and ameliorate their effects. The origins of global warming include the production of $\mathrm{CO}_{2}$ from human activities, particularly from burning fossils fuels such as oil, coal, and natural gas to provide energy for motor vehicles, heat sources, and power plants. Other sources of $\mathrm{CO}_{2}$ emissions are forest fires, forest burning, and land clearing for both plantation land and agricultural land. In particular, forest fires cause greater emissions than forest burning and land clearing, and the burnt areas are much larger due to the long dry-season. Similarly, in the cement manufacturing 
industry, $\mathrm{CO}_{2}$ is produced from the calcination of limestone, which is the main raw material in cement production. Despite efforts to reduce $\mathrm{CO}_{2}$ from cement plants, a significant reduction in $\mathrm{CO}_{2}$ emissions has not been achieved to date. The production of $\mathrm{CO}_{2}$ by the carbon black manufacturing industry, where carbon black is used as a filler in rubber, is another important source of $\mathrm{CO}_{2}$ emissions. Carbon black is produced using the thermal decomposition method or the partial combustion method, using oil or natural gas as raw material.

Among its other applications, carbon black is used for making rubber compounds in the vehicle tire industry. The role of carbon black is still very dominant in rubber compound manufacturing because carbon black can provide significant reinforcement effects and can reduce the amount of rubber used. While silica is an alternative material to carbon black that can also act as a reinforcement in rubber compounds, its reinforcement effect is inferior to that of carbon black. As reported by Hasan et al. (2019), local clay includes a fairly large amount of silica, which means that the nature of local clay is fairly similar to the nature of silica. Therefore, it is important to use local clay as a filler. Although the effect of clay as a filler has a smaller reinforcing effect on vulcanized rubber compared to the use of carbon black fillers, clay surface modification is needed to increase compatibility with the rubber matrix.

Local clay containing $50.83-75.29 \%$ silica is a common silica source in nature (Hasan et al., 2019) that is five times more common than coal. Therefore, this clay is an interesting possible filler material in rubber compounds. The type of clay in this study is kaolin clay, as described in Figure 8. The use of clay as a rubber filler has been studied by many researchers, including Goodman and Riley (2012), Ismail and Mathialagan (2011), Lalikova et al. (2011), Ruamcharoen et al. (2014), Szustakiewicz et al. (2013), Zhang et al. (2012), and Zhang et al. (2010, 2014), and modified clay has also been widely examined-for example, in the work by Ambre et al. (2008), Jagtap et al. (2013), Kord et al. (2017), Ogbebor et al. (2015a, 2015b), Peter et al. (2016), Puglia et al. (2016), Saritha et al. (2012), Sheikh et al. (2017), Sreelekshmi et al. (2016, 2017), Sukumar and Menon (2008), and Yahaya et al. (2009). Most of the types of clay used by researchers are kaolin clay, in addition to bentonite and montmorillonite clay.

A wide variety of chemicals have been used by researchers to modify clay, such as the metal chlorides used by Lalikova et al. (2011), the fatty acid salt used by Zhang et al. (2014), the hydrazine hydrate used by Sukumar and Menon (2008), the dimethyl, benzyl, dehydrogenated tallow, and quarternary ammonium used by Saritha et al. (2012), the 3mercaptoprophyltrimethoxysilane used by Sheikh et al. (2017), the hexamethylenediamine used by Sreelekshmi et al. (2017), the dimethyldioctadecylammonium and bis(4hydroxybuthyl)methyldioctadecylammonium used by Nam et al. (2004), and the octadecylamine used by Praveen et al. (2009), Nigam et al. (2012), and Manchado et al. (2003). In general, this clay modification aims to increase the adsorption on the clay surface so that the clay can function better as a filler. An increase in surface adsorption is carried out not only on the clay but also on the adsorbent (Wilson and Mahmud, 2015; Anuar et al., 2019; Kusrini et al., 2019). Here, clay also functions as an adsorbent for rubber molecules on its surface.

Therefore, this study aims to compare the curing characteristics and physical properties of natural rubber composites using clay and dodecylamine-modified clay as the fillers. The modified clay was analyzed by FTIR spectroscopy and X-ray diffraction while the natural rubber compounds were examined by TA/DTA and SEM. The surface of vulcanized natural rubber was analyzed by AFM. 


\section{Methods}

\subsection{Materials}

Local clay from the coal mining area of Tanjung Enim, Indonesia, and natural rubber RSS 1 obtained from PTPN IX, Semarang, Indonesia, were used in this study. The rubber chemicals were Sulfur Midas SP-325 (Miwon Chemicals Co., Ltd, Korea), TMTD Accelerator (Qingdao Ever Century Trading Co., Ltd. China), ZnO Zinkoxyd Aktiv UN 3077 and TMQ Vulkanox HS/LG (LANXESS Deutschland GmbH, Germany), stearic acid Aflux 52 (Rhein Chemie Rheinau Mannheim GmbH, Germany), and oil Minarex (Pertamina, Indonesia). Dodecylamine (Merck, Germany) was used as the clay modifier. All of these rubber chemicals and clay modifiers were used as received, with no further modification.

\subsection{Procedures}

\subsubsection{Modified clay process}

Clay (15 g) was prepared and dispersed into distilled water at $80^{\circ} \mathrm{C}$. Dodecylamine (3.89 g) and $\mathrm{HCl}(10 \mathrm{~N}, 2.1 \mathrm{~mL})$ were then added to distilled water (300 $\mathrm{mL})$. These two mixtures were mixed and stirred for one hour at $80^{\circ} \mathrm{C}$. Modified clay was obtained by filtering and washing with alcohol and distilled water in a ratio of $1+1$. The washing water test used a $0.01 \mathrm{~N} \mathrm{AgNO}_{3}$ solution to determine the residual $\mathrm{HCl}$ content. The modified clay was then vacuum-dried at $75^{\circ} \mathrm{C}$ for three to four days and stored in a desiccator. The flow diagram for this procedure is shown in Figure 1.

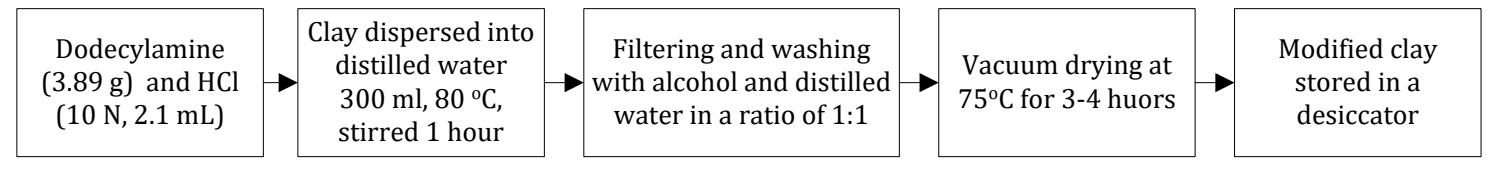

Figure 1 Flow diagram of modified clay process

\subsubsection{Rubber mixing process}

Rubber was milled using an open two-roll mill (Berstorff, Germany) with a capacity of $1 \mathrm{~kg}$. During the grinding process, the rubber was mixed with rubber chemicals consisting of sulfur, ZnO, stearic acid, TMTD, oil, TMQ, and clay as well as modified clay fillers to produce a natural rubber compound. The contents of the clay and modified clay in rubber were approximately $15 \mathrm{phr}$ (parts per hundred rubbers) each. The milling process temperature was approximately $65^{\circ} \mathrm{C}$. The natural rubber formulation is stated in Table 1 .

Table 1 The formulation for natural rubber mixing, (1) using clay and (2) using modified clay

\begin{tabular}{lcc}
\hline \multirow{2}{*}{ Ingredients } & \multicolumn{2}{c}{ Compounds, phr } \\
\cline { 2 - 3 } & 1 & 2 \\
\hline Natural rubber RSS 1 & 100 & 100 \\
Stearic acid & 2 & 2 \\
ZnO & 5 & 5 \\
TMQ & 2 & 2 \\
TMTD & 0.5 & 0.5 \\
Sulfur & 3 & 3 \\
Oil & 3 & 3 \\
clay & 15 & - \\
Modified clay & - & 15 \\
\hline
\end{tabular}




\subsubsection{Characterization of curing and physical properties of natural rubber}

The natural rubber compound was tested for its curing properties at $150^{\circ} \mathrm{C}$, using a Rheometer MDR 2000 (Alpha Technology, USA). Then, physical properties-including the tensile strength, elongation at break, 300\% modulus, and tear resistance-were tested using a Lloyd 2000 (Lloyd Instruments Ltd., UK) with a tensile speed of $50 \mathrm{~cm} / \mathrm{min}$, according to the ASTM standard. The compression set, de Mattia flex cracking, and shore A hardness were also tested according to the ASTM standard.

\subsubsection{Clay and modified clay characterization}

The pretreatment of the clay and modified clay samples was carried out using powderpressed $\mathrm{KBr}$ pellets and an FTIR Alpha instrument (Bruker, Germany). FTIR spectra were recorded in the 500-4000 $\mathrm{cm}^{-1}$ range. XRD measurements were carried out using a Bruker D8 Advance X-ray diffractometer (Bruker, Germany) with $\mathrm{Cu}$ k $\alpha$ radiation at $\lambda=1.54060 \AA$, a current of $20 \mathrm{~mA}$, and voltage of $40 \mathrm{kV}$. XRD patterns for the clay and modified clay samples were determined at a scan rate of $0.02 \% / \mathrm{s}$ in the $2 \theta$ range of $2-90^{\circ}$. Natural rubber compound samples with lateral dimensions of approximately $10 \mathrm{~mm} \times 10 \mathrm{~mm}$ and a thickness of $3 \mathrm{~mm}$ were used to examine the dispersion of the fillers in the natural rubber composites using an SEM SU3500 instrument (Hitachi, Japan). Prior to the SEM testing, the samples were pretreated by ion sputtering (gold coating). In addition to SEM, an AFM $5300 \mathrm{E}$ scanning probe microscope (Hitachi, Japan) was used to examine the surface of the natural rubber vulcanizates and surface images were obtained. The dimensions of the vulcanized natural rubber sample were approximately $10 \mathrm{~mm} \times 10 \mathrm{~mm} \times 2 \mathrm{~mm}$. Thermal analysis using a TA/DTA STA 7300 instrument (Hitachi, Japan) was performed at a heating rate of $10^{\circ} \mathrm{C} / \mathrm{min}$ in a temperature range of $30-500^{\circ} \mathrm{C}$ under a nitrogen atmosphere.

\section{Results and Discussion}

\subsection{Curing Analysis of Natural Rubber Composites Compound}

Figure 2 compares the curing characteristics of the natural rubber composites obtained using (1) clay and (2) dodecylamine-modified clay fillers.

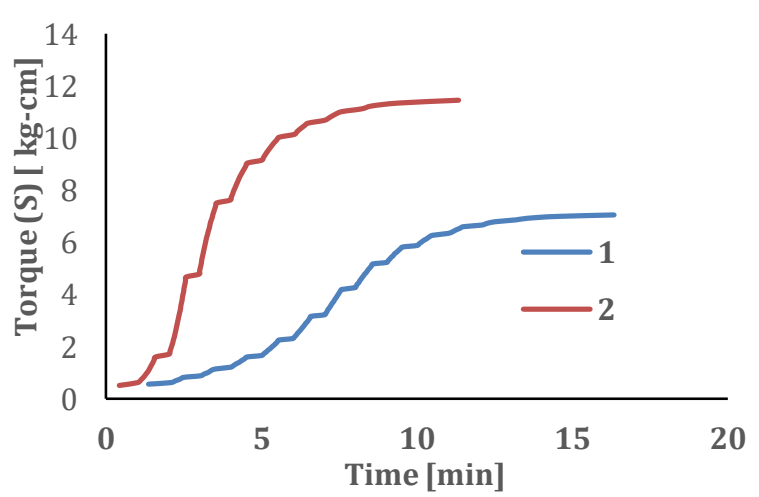

(a) Rheograph of Natural Rubber Compound

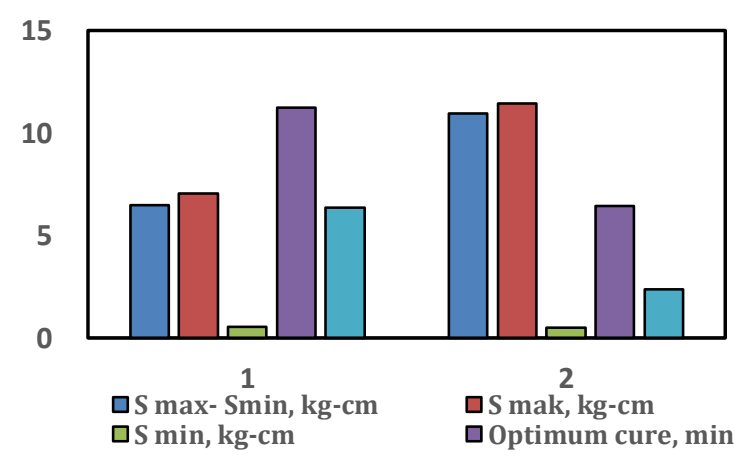

(b) Curing Characteristics

Figure 2 Curing characteristics of natural rubber composites, (1) using unmodified clay and (2) using modified clay

It was observed that $S_{\max }$ increased quite significantly while $S_{\min }$ decreased and the optimal cure rate $\left(\mathrm{t}_{90}\right)$ and scorch time dropped dramatically due to the use of the modified clay. These results indicate that the crosslink density increases and the time for the vulcanization reaction decreases due to the clay modification. This finding means that the vulcanization reaction rate is increased with the addition of modified clay filler compared to when the clay filler is used. Evidence that the vulcanization reaction increases as a result of the use of 
modified clay filler, in the shorter vulcanization time, was that the torque achieved by the composite is much higher than that of the composite torque using only unmodified clay fillers (see Figure 2). This finding means that modified clay can more easily absorb rubber molecules on its surface, so it can be a good filler. According to Sreelekshmi et al. (2016), the chemically bounded oligomers form a film on the clay surface, thus improving compatibility with the rubber matrix. The organofunctional groups of the oligomer film react with rubber during vulcanization.

\subsection{Physical Properties of Vulcanized Natural Rubber Composites}

The physical properties of the natural rubber composites using the clay filler and modified clay are shown in Figures 3-5. Figure 3 shows an overview of the elongation at break results, while Figure 4 shows the results obtained for the hardness, tensile strength, and modulus of $300 \%$, and Figure 5 shows the results for the tear strength, compression set, and flex cracking.

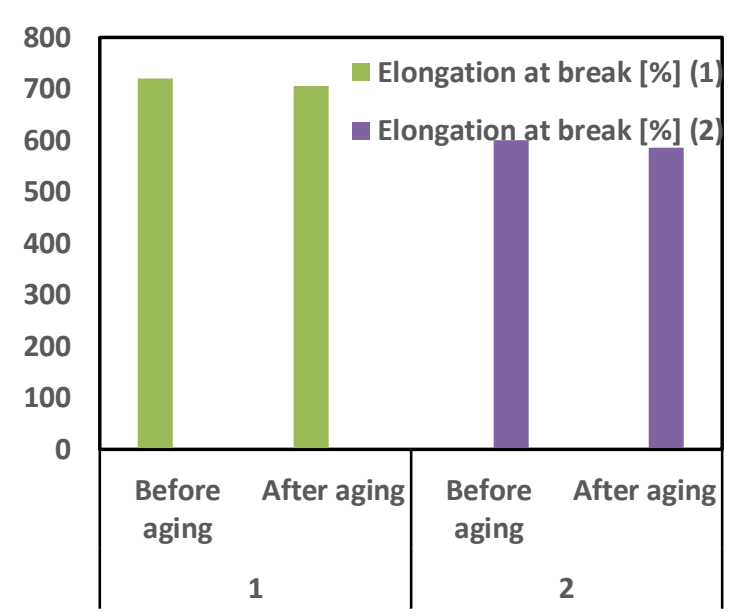

Figure 3 Elongation at break as a function of aging, (1) using unmodified clay and (2) using modified clay

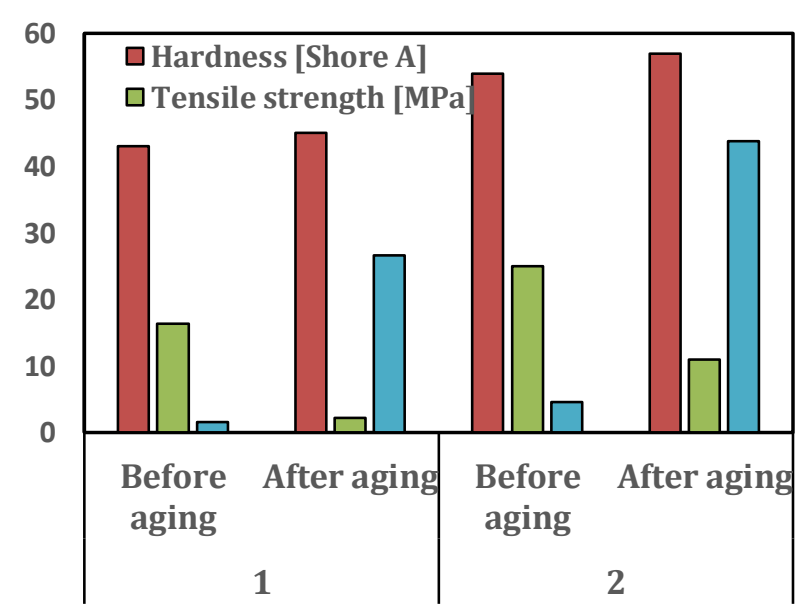

Figure 4 Physical properties of natural rubber composite (hardness, tensile strength, and modulus 300\%), (1) using clay filler (2) using modified clay filler

Figure 3 shows that elongation at break decreased from Sample 1 to Sample 2, and a decrease in elongation at break was observed after aging for both samples. Elongation at break decreased due to an increase in the vulcanization reaction that stiffened the rubber vulcanizates. This stiffness affected the elongation at break. The reduction in the elongation at break after aging indicates that a vulcanization reaction that affects the sample stiffness continued. This increase in stiffness caused a decrease in the elongation at break.

Figure 4 shows that hardness rose after aging for both samples 1 and 2, caused by the vulcanization reaction continuing during the aging process. The hardness of Sample 2 was higher than that of Sample 1, indicating that the modified clay has a significant effect. A similar effect was also observed for modulus 300\%. However, the tensile strength decreased considerably for Sample 1 and Sample 2. The increased vulcanization reaction caused the crosslink density to increase, as Figure 2 shows, stiffening the rubber vulcanizates. The stiffness of vulcanized rubber can lead to a decrease in tensile strength.

Figure 5 shows the increase in tear strength and compression set of the natural rubber composites while flex cracking did not change. This increase had an impact on the increased vulcanization reaction of samples 1 and 2 . 


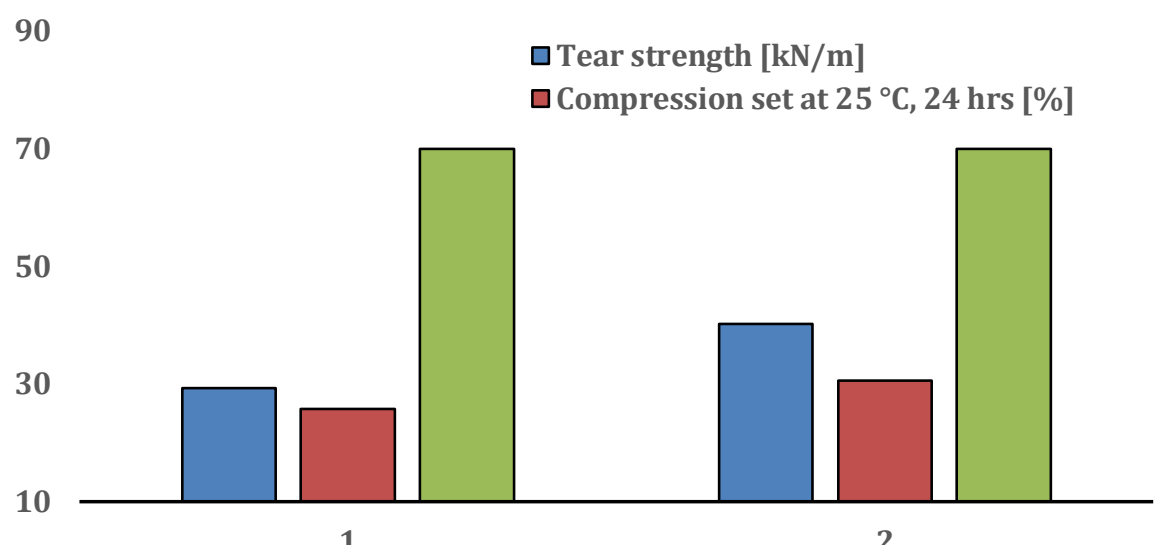

Figure 5 Physical properties of natural rubber composite sample 1 and sample 2: tear strength, compression set, and flex cracking, (1) using clay filler and (2) using modified clay filler

\subsection{FTIR Spectra}

As a mineral, clay does not show a $\mathrm{C}-\mathrm{H}$ bond with an absorption band at approximately $2852 \mathrm{~cm}^{-1}$. The presence of this $\mathrm{C}-\mathrm{H}$ stretching band in the FTIR spectrum indicates the modification of the clay (see Figure 6). While the FTIR spectrum should display a sharp peak at $3431 \mathrm{~cm}^{-1}$ due to the primary amine group (NH stretching) in dodecylamine, this peak was not observed-most likely due to the presence of a broad peak at $3431 \mathrm{~cm}^{-1}$ arising from the $\mathrm{OH}$ bonds in the clay. Similarly, the $\mathrm{N}-\mathrm{H}$ bending band at approximately $1640 \mathrm{~cm}^{-1}$ may have been overlapping with the $\mathrm{O}-\mathrm{H}$ band at the same energy. These characteristics were also found by Lalikova et al. (2011), Sukumar and Menon (2008), and Sreelekshmi et al. (2017).

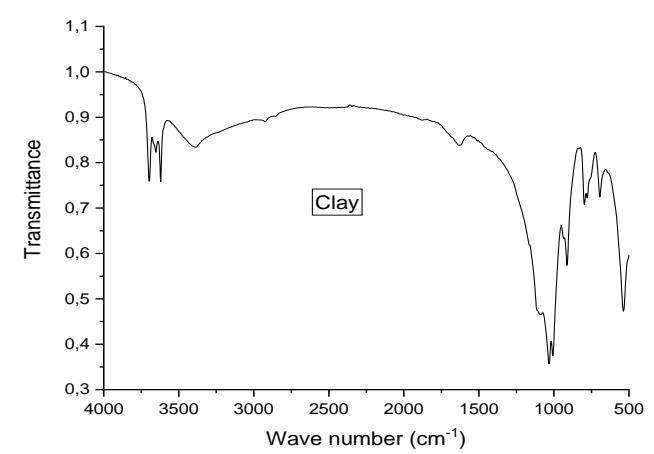

(a) Clay

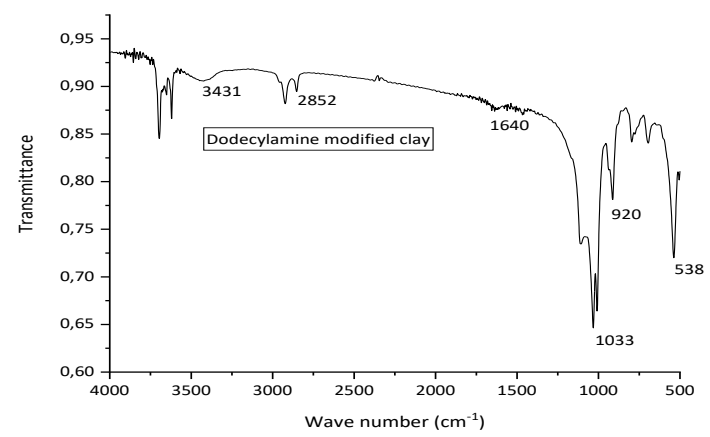

(b) Modified clay

Figure 6 FTIR spectra of clay and modified clay

\subsection{AFM Studies}

Figure 7 shows that the natural rubber composite vulcanizates of the two samples exhibited different surface morphology. This difference was caused by differences in the surface dimensions of the unmodified clay and modified clay. Figure 7 also shows that, for a sample height of approximately $4 \mu \mathrm{m}$, modified clay provided a relatively bumpy surface compared to the surface obtained when unmodified clay was used as the filler. This difference was caused by the changes in the dimensions of the modified clay, and it was also reported by Nam et al. (2004), Nigam et al. (2012), and Suresha et al. (2013). Figure 7 also shows that the distribution of modified clay particles in vulcanized natural rubber was better compared to the use of unmodified clay fillers. (Note the frequency distribution curve 
next to the image in Figure 7). The frequency distribution of modified clay is relatively flat compared to the use of unmodified clay.
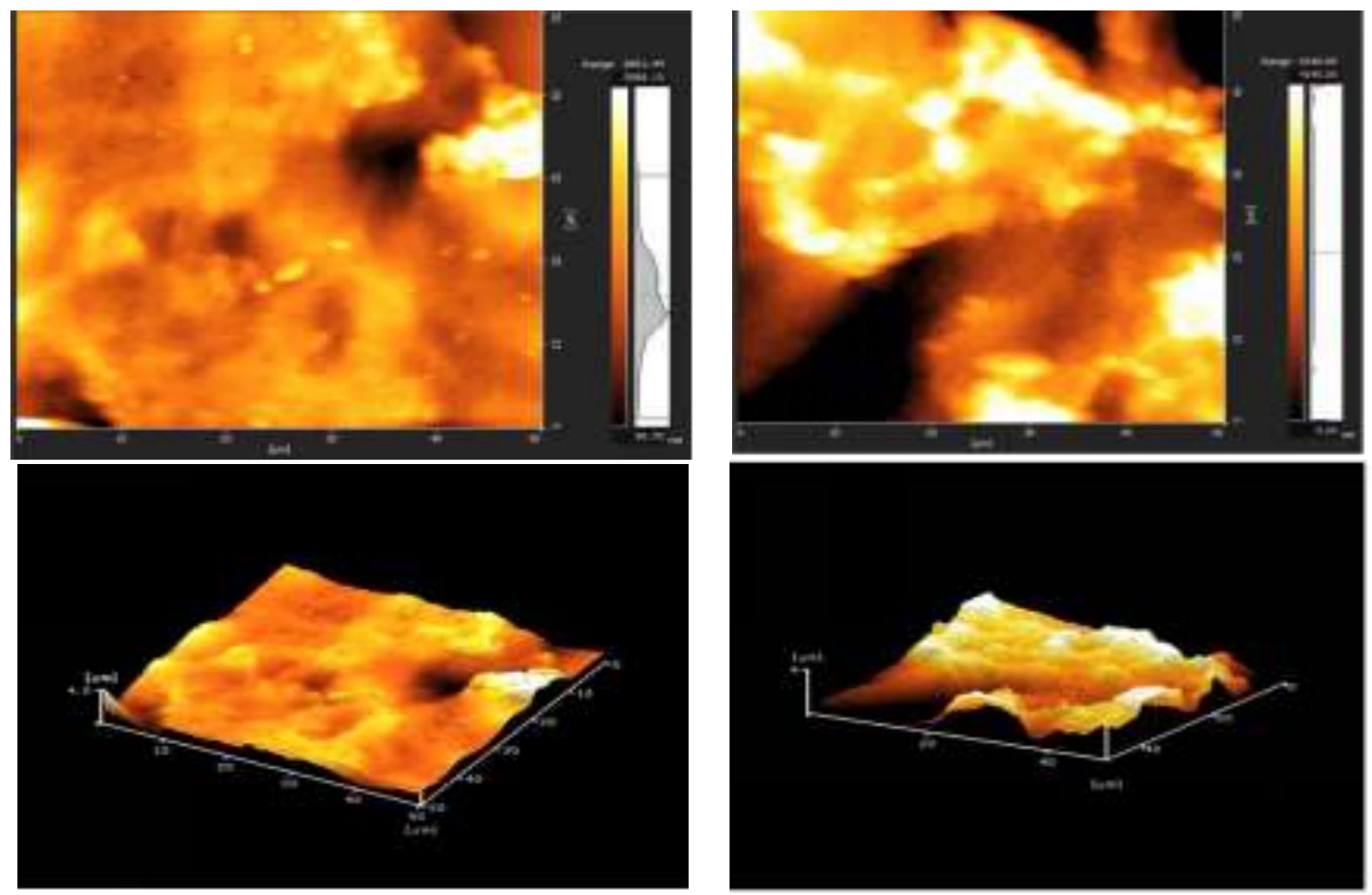

(a)

(b)

Figure 7 AFM images of the natural rubber composites filled by clay: (a) unmodified clay used as the filler; and (b) modified clay used as the filler

\subsection{XRD Analysis}

The diffraction patterns of clay and modified clay presented in Figure 8 demonstrate the modification of the clay, as observed from the different diffraction patterns obtained for the two samples.

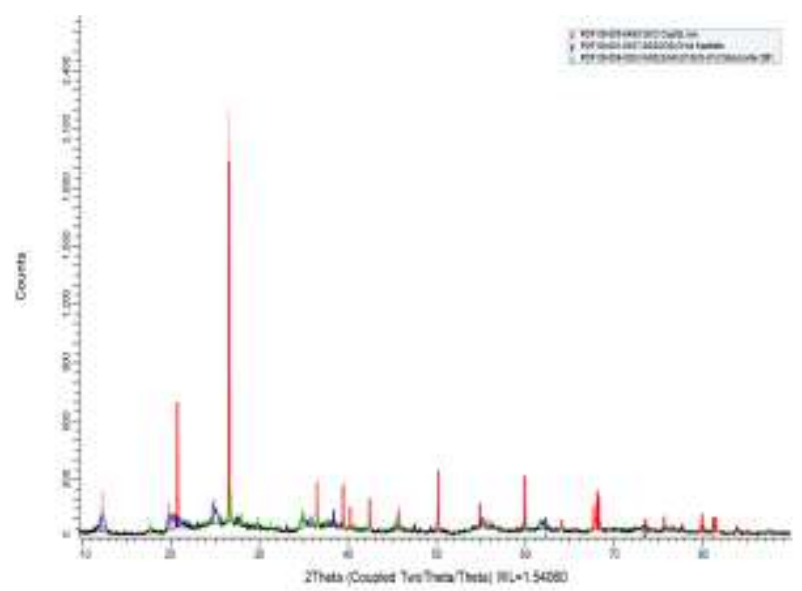

(a)

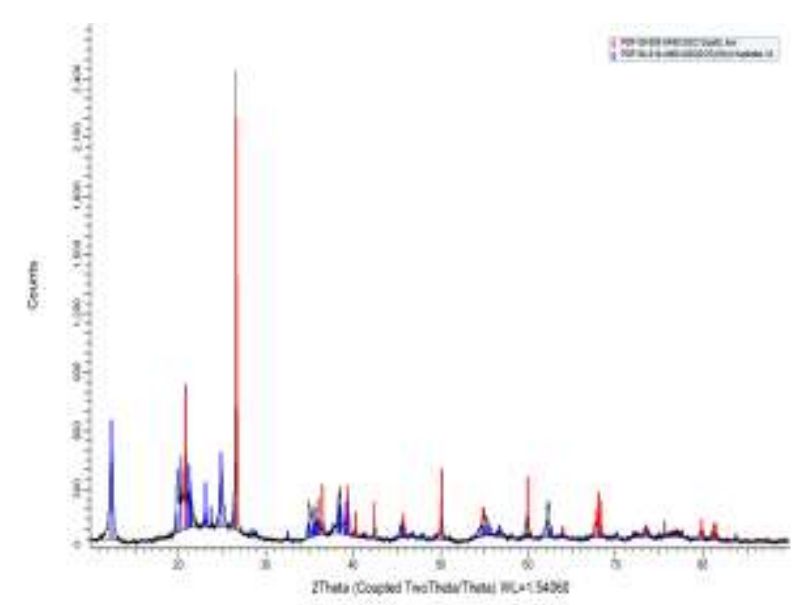

(b)

Figure 8 XRD analysis of clay and modified clay: (a) diffraction pattern of clay; and (b) diffraction pattern of modified clay 
This difference can be explained by changes in the dimensions of the compounds' crystals contained in the clay, as presented in Table 2. In addition to the changes in the dimensions of the crystals in the modified clay, new peaks were observed at $2 \theta$ of $20.258^{\circ}$ with a dspacing of $4.33923 \AA$ and at $2 \Theta$ of $21.373^{\circ}$ with a d-spacing of $4.15406 \AA$. Assad et al. (2014) reported that clay modification was indicated by a change in the diffraction peak intensity from 11.7948 to 18.7583 at $2 \theta$ of approximately $5^{\circ}$. The peak at this $2 \theta$ angle can also be observed in Figure 8, but with a different intensity from that reported by Assad et al. (2014).

Table 2 Crystal dimension parameters of (a) clay and (b) modified clay

\begin{tabular}{clcc}
\hline \multirow{2}{*}{ Minerals } & \multicolumn{2}{c}{ Crystal parameters } & \multicolumn{2}{c}{ Fillers used } \\
\cline { 2 - 4 } Quartz, low & (a) & $(\mathrm{b})$ \\
\hline & Crystal density, $\left(\mathrm{g} / \mathrm{cm}^{3}\right)$ & 2.647 & 2.640 \\
& Lattice parameters & & \\
& $-\mathrm{a}(\AA)$ & 4.914 & 4.919 \\
& $-\mathrm{c}(\AA)$ & 5.406 & 5.412 \\
\hline \multirow{5}{*}{ Krystal density, $\left(\mathrm{g} / \mathrm{cm}^{3}\right)$} & 2.565 & 2.590 \\
& Lattice parameters & & \\
& $-\mathrm{a}(\AA)$ & 5.115 & 5.171 \\
Kaolinite-1A & $-\mathrm{b}(\AA)$ & 9.137 & 8.947 \\
& $-\mathrm{c}(\AA)$ & 7.405 & 7.404 \\
& Alpha $\left({ }^{\circ}\right)$ & 92.53 & 91.87 \\
& Beta $(\mathrm{o})$ & 104.75 & 104.7 \\
& Gamma (o) & 89.488 & 89.756 \\
\hline
\end{tabular}

\subsection{SEM Studies}

SEM analyses were carried out for the clay and modified clay samples, as shown in Figure 9, and for the natural rubber composites, as shown in Figure 10.
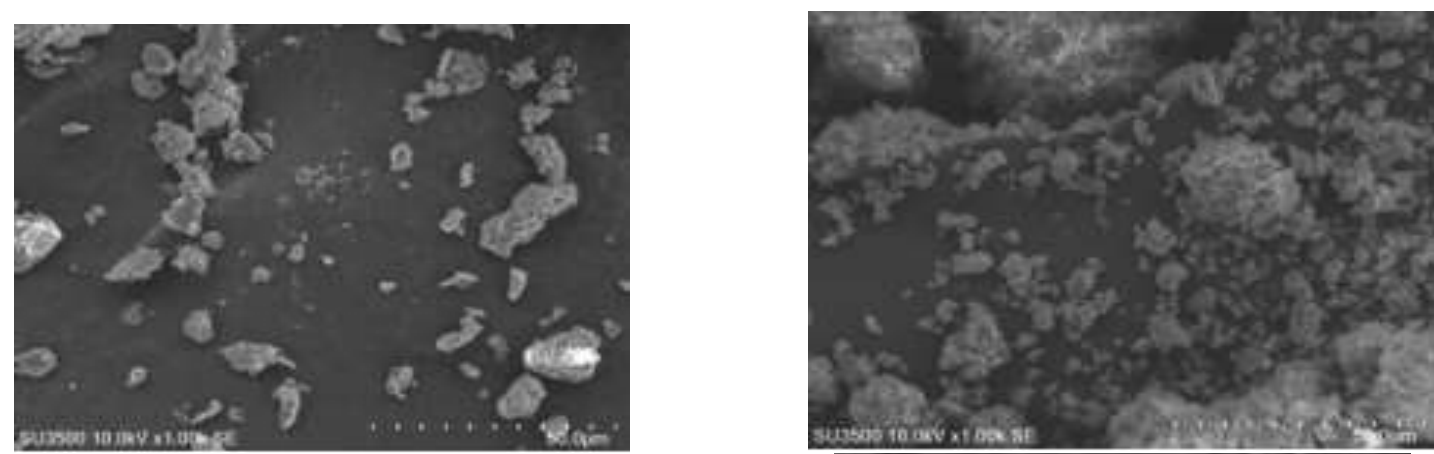

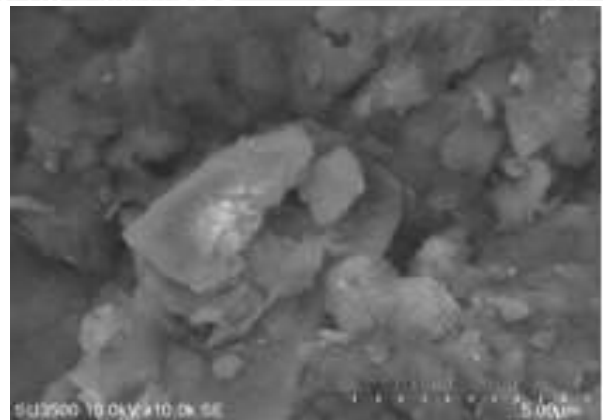

(a)

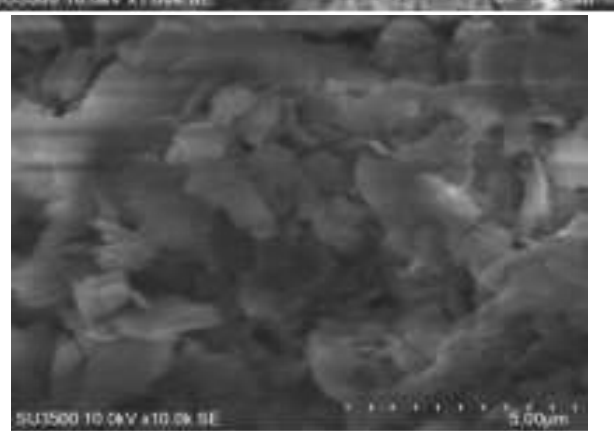

(b)

Figure 9 SEM analysis of: (a) clay; and (b) modified clay

Figures 9a and 9b show the clay and modified clay SEM images, respectively. The image presented in Figure $9 \mathrm{~b}$ indicates a smoother surface and is more diffuse compared to the 
image in Figure 9a. The filler surface contour in Figure 9 shows similarities in the surface roughness of the natural rubber compound contained in Figure 10. This observation on the contour is supported by the image shown in Figure 7, where the frequency distribution of the filler particles supports this explanation.

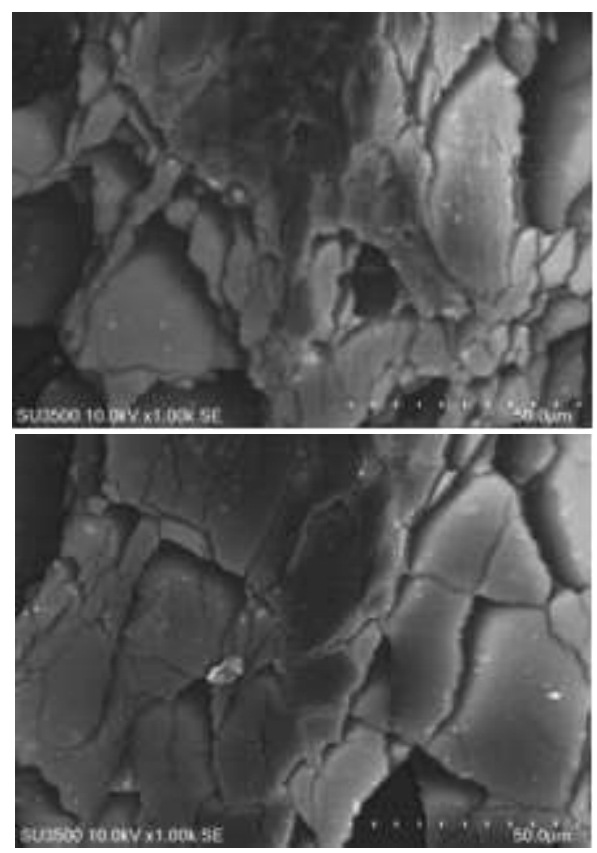

(a)

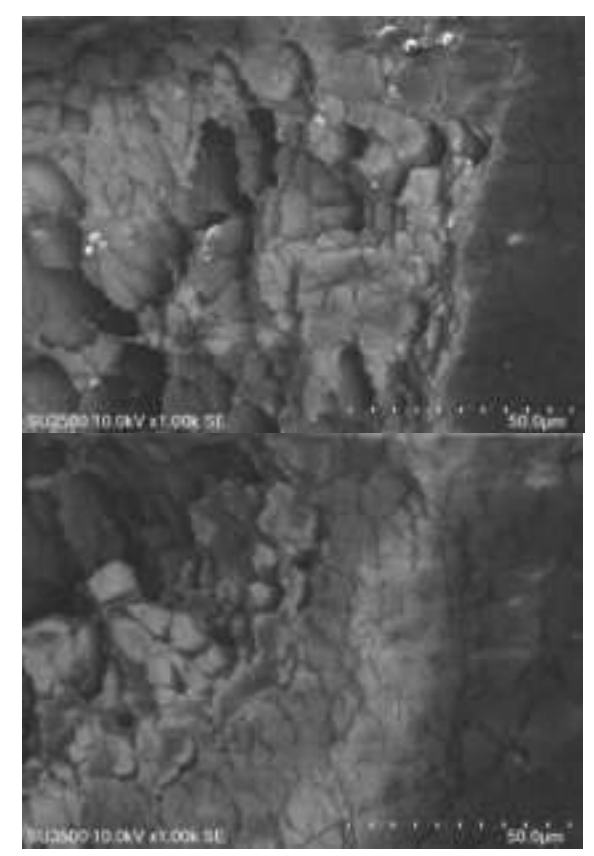

(b)

Figure 10 SEM analysis of natural rubber composites, (a) natural rubber compound with the clay filler and (b) natural rubber compound with the modified clay filler

\subsection{TA/DTA Analyses}

Figure 11a shows that the peak of the mass reduction rate of the natural rubber compound using clay (DTA1) of $1.37 \% / \mathrm{min}$ was located at $370.89^{\circ} \mathrm{C}$ while, for the natural rubber compound that used modified clay (DTA2), the peak mass reduction rate of $1.26 \% / \mathrm{min}$ was observed at $370.06^{\circ} \mathrm{C}$.

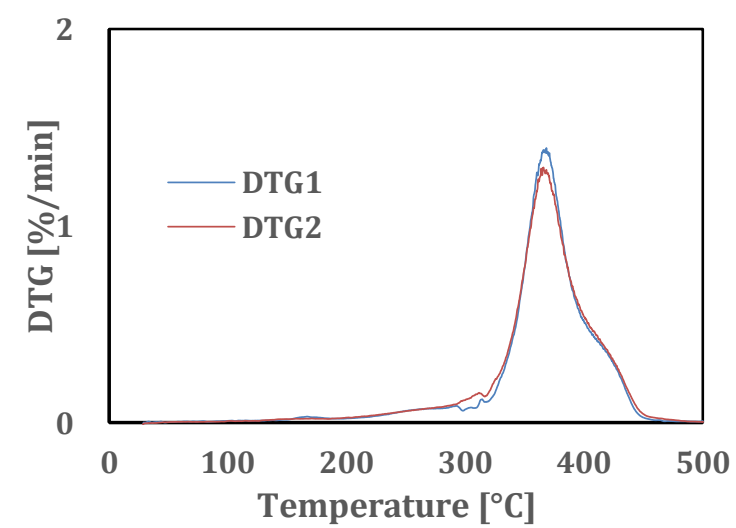

(a)

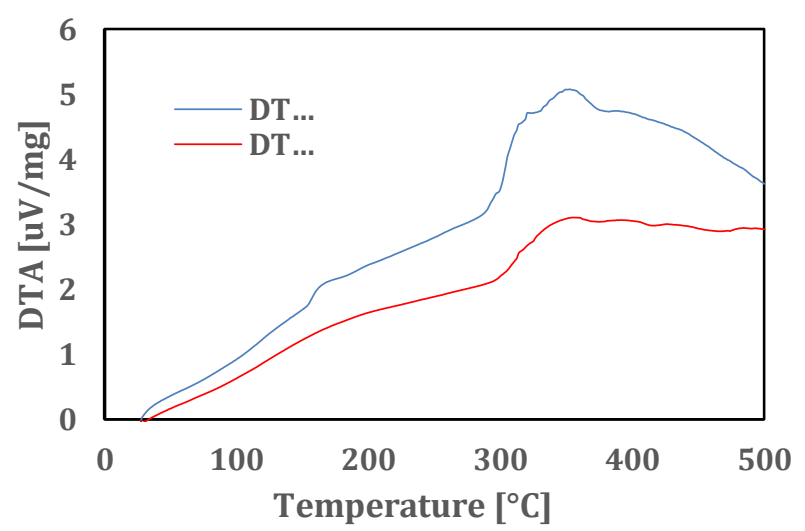

(b)

Figure 11 Thermal analysis of natural rubber compound (a) using clay and (b) using modified clay

The rate of the volume reduction in mass DTA2 was generally lower than that in DTA1. The highest rate of DTA2 was $5.07 \mu \mathrm{V} / \mathrm{mg}$ at $358.10^{\circ} \mathrm{C}$ while, for DTA1, the highest rate of 5.05 $\mu \mathrm{V} / \mathrm{mg}$ was obtained at a temperature of $358.10^{\circ} \mathrm{C}$, as shown in Figure $11 \mathrm{~b}$. It can be 
concluded from Figure 10 that the DTA2 for Sample 2 was more stable than the DTA1 for Sample 1. The thermal stability of natural rubber filled by organo-modified kaolin was also reported by Zhang et al. (2012), who found that natural rubber using organo-modified kaolin showed a dramatic decrease in mass loss.

\section{Conclusions}

Modified clay has a better effect on the curing characteristics and physical properties of natural rubber than unmodified clay. The vulcanized rubber stiffness, due to an increased vulcanization reaction in the natural rubber, leads to changes in the physical properties of the natural rubber. An analysis of FTIR spectra shows that the clay has been modified with dodecylamine. These results agree with the XRD analysis results that indicate a change in the dimensions of the clay crystal. SEM and AFM images provide consistent information about the filler dispersion in the natural rubber. Modified clay dispersion is better than that of unmodified clay, and this finding supports the explanation of the different physical properties of the obtained vulcanized natural rubber. TA/DTA thermal stability analyses show that natural rubber compounds that use modified clay as the filler are more stable than those using only unmodified clay filler.

\section{Acknowledgements}

This work was supported by the Directorate General of Strengthening Research and Development, Ministries of Research, and Higher Education, Republic of Indonesia, with the scheme of Higher Education Applied Research under contract number 153/SP2H/LT/DRPM/2019, dated March 11, 2019.

\section{References}

Ambre, A., Jagtap, R., Dewangan, B., 2008. ABS Nanocomposites Containing Modified Clay. Journal of Reinforced Plastics and Composites, Volume 28(3), pp. 343-352

Anuar, F.I., Hadibarata, T., Muryanto, M., Yuniarto, A., Priyandoko, D., Sari, A.A., 2019. Innovative Chemically Modified Biosorbent for Removal of Procion Red. International Journal of Technology, Volume 10(4), pp. 776-786

Assad, J.N., El-Nashar, D.E., Mansour, S.H., 2014. Effect of Modified Clay and $\mathrm{Mg}(\mathrm{OH}) 2$ on the Properties of Ethylene Propylene Diene Monomer/Silicon Rubber Nanocomposites. In: Proceedings of the Institution of Mechanical Engineers Part $\mathrm{N}$ Journal of Nanoengineering and Nanosystems, Volume 229(3), pp. 121-130

Goodman, H., Riley, A., 2012. Clay Mineral Products and Their Use in Rubber Compositions. United States: Imerys Minerals Limited, Par Cornwall (GB). Patent US8183316B2

Hasan, A., Kalsum, L., Yerizam, M., Junaidi, R., Taufik, M., Aznury, M., Fatria, F., 2019. Potential of Clay in Coal Mining of Tanjung Enim Area as a Filler on Rubber Compound. In: Proceeding of $2^{\text {nd }}$ Forum in Research, Science, and Technology. Palembang, Indonesia, IOP Conference. Series: Journal of Physics, Volume 1167(2019), 012042, IOP Publishing

Ismail H., Mathialagan M., 2011. Curing Characteristics, Morphological, Tensile and Thermal Properties of Bentonite-Filled Ethylene-Propylene-Diene Monomer (EPDM) Composites. Polymer-Plastics Technology and Engineering, Volume 50(14), pp. 14211428

Jagtap, S.B., Rao, V.S., Ratna, D., 2013. Preparation of Flexible Epoxy/Clay Nanocomposites: Effect of Preparation Method, Clay Modifier and Matrix Ductility. Journal of Reinforced Plastics and Composites, Volume 32(3), pp. 183-196 
Kord, B., Ravanfar, P., Ayrilmis, N., 2017. Influence of Organically Modified Nanoclay on Thermal and Combustion Properties of Bagasse Reinforced HDPE Nanocomposites. Journal of Polymers and the Environment, Volume 25(4), pp. 1198-1207

Kusrini, E., Putra, N., Siswahyu, A., Tristatini, D., Prihandini, W.W., Alhamid, M.I., Yulizar, Y., Usman, A., 2019. Effects of Sequence Preparation of Titanium Dioxide-water Nanofluid using Cetyltrimethylammonium Bromide Surfactant and $\mathrm{TiO}_{2}$ Nanoparticles for Enhancement of Thermal Conductivity. International Journal of Technology, Volume 10(7), pp. 1453-1464

Lalikova, S., Pajtasova, M., Chromcıkova, M., Liska, M., Sutinska, V., Olsovsky, M., Ondrusova, D., Mojumdar, S.C., 2011. Investigation of Natural Rubber Composites with Addition of Montmorillonite Fillers using Thermal Analysis. Journal of Thermal Analysis and Calorimetry, Volume 104, pp. 969-973

Manchado, M.A.L., Arroyo, M., Herrero, B., Biagiotti, J., 2003. Vulcanization Kinetics of Natural Rubber-Organoclay Nanocomposites. Journal of Applied Polymer Science, Volume 89(1), pp. 1-15

Nam, P.H., Fujimori, A., Masuko, T., 2004. Flocculation Characteristics of Organo-modified Clay Particles in Poly(L-lactide)/Montmorillonite Hybrid Systems. e-Polymers, Volume 4(1), pp. 1-7

Nigam, V., Soni, H., Saroop, M., Verma, G.L., Bhattacharya, A.S., Setua, D.K., 2012. Thermal, Morphological, and X-Ray Study of Polymer-Clay Nanocomposites. Journal of Applied Polymer Science, Volume 124(4), pp. 3236-3244

Ogbebor, O.J., Oikiemen, F.E., Ogbeifun, D.E., Okwo, U.N., 2015a. Organomodified Kaolin as Filler for Natural Rubber. Chemical Industry \& Chemical Engineering Quarterly, Volume 21(4), pp. 477-484

Ogbebor, O.J., Oikiemen, F.E., Ogbeifun, D.E., Okwo, U.N., 2015b. Preparation and Properties of Organokaolin Natural Rubber Latex Vulcanizate. Advance in Materials, Volume 4(4), pp. 75-79

Peter, R., Sreelekshmi, R.V., Menon, A.R.R., 2016. Cetyltrimethyl Ammonium Bromide Modified Kaolin as a Reinforcing Filler for Natural Rubber. Journal of Polymers and the Environment, Volume 26(1), pp. 39-47

Praveen, S., Chattopadhyay, P.K., Albert, P., Dalvi, V.G., Chakraborty, B.C., Chattopadhyay, S., 2009. Synergistic Effect of Carbon Black and Nanoclay Fillers in Styrene Butadiene Rubber Matrix: Development of Dual Structure. Composites Part A: Applied Science and Manufacturing, Volume 40(3), pp. 309-316

Puglia, D., Fortunati, E., D’Amico, D.A., Miri, V., Stoclet, G., Manfredi, L.B., Cyras, V.P., Kenny, J.M., 2016. Influence of Processing Conditions on Morphological, Thermal and Degradative Behavior of Nanocomposites based on Plasticized Poly(3Hydroxybutyrate) and Organo-Modified Clay. Journal of Polymers and the Environment, Volume 24(1), pp. 12-22

Ruamcharoen, J., Ratana, T., Ruamcharoen, P., 2014. Bentonite as a Reinforcing and Compatibilizing Filler for Natural Rubber and Polystyrene Blends in Latex Stage. Polymer Engineering and Science, Volume 54(6), pp. 1436-1443

Saritha, A., Joseph, K., Thomas, S., Muraleekrishnan, R., 2012. The Role of Surfactant Type and Modifier Concentration in Tailoring the Properties of Chlorobutyl Rubber/Organo Clay Nanocomposites. Journal of Applied Polymer Science, Volume 124, pp. 4590-4597

Sheikh, S.H., Yin, X., Ansyarifar, A., Yendall, K., 2017. The Potential of Kaolin as a Reinforcing Filler for Rubber Composites with New Sulfur Cure Systems. Journal of Reinforced Plastic and Composites, Volume 36(16), pp. 1132-1145 
Sukumar, R., Menon, A.R.R., 2008. Organomodified Kaolin as a Reinforcing Filler for Natural Rubber. Journal of Applied Polymer Science, Volume 107(6), pp. 3476-3483

Suresha, B., Devarajaiah, R.M., Pasang, T., Ranganathaiah, C., 2013. Investigation of OrganoModified Montmorillonite Loading Effect on the Abrasion Resistance of Hybrid Composites. Materials and Design, Volume 47, pp. 750-758

Sreelekshmi, R.V., Brahmakumar, M., Sudha, J.D., Menon, A.R.R., 2017. Studies on Natural Rubber Containing Kaolin Modified with Hexamethylenediamine Derivative of Phosphorylated Cashew Nut Shell Liquid Prepolymer. Applied Clay Science, Volume 141, pp. 171-179

Sreelekshmi, R.V., Sudha, J.D., Menon, A.R.R., 2016. Novel Organomodified Kaolin/Silica Hybrid Fillers in Natural Rubber and Its Blend with Polybutadiene Rubber. Polymer Bulletin, Volume 74(3), pp. 783-801

Szustakiewicz, K., Cichy, B., Gazinska, M., Piglowski, J., 2013. Comparative Study on Flame, Thermal, and Mechanical Properties of HDPE/Clay Nanocomposites with MPP or APP. Journal of Reinforced Plastics and Composites, Volume 32(14), pp. 1005-1017

Wilson, L.D., Mahmud, S.T., 2015. The Adsorption Properties of Surface-modified Mesoporous Silica Materials with $\beta$-Cylodextrin. International Journal of Technology, Volume 6(4), pp. 533-545

Yahaya, L.E., Adebowale, K.O., Menon, A.R.R., 2009. Mechanical Properties of Organomodified Kaolin/Natural Rubber Vulcanizates. Applied Clay Science, Volume 46(3), pp. 283-288

Zhang, Q., Zhang, Y., Wang, Y., 2012. Mechanical and Thermal Properties of Kaolin/Natural Rubber Nanocomposites Prepared by the Conventional Two-Roll Mill Method. Applied Mechanics and Materials, Volume 164, pp. 142-145

Zhang, Y., Liu, Q., Zhang, Q., Lu, Y., 2010. Gas Barrier Properties of Natural Rubber/Kaolin Composites Prepared by Melt Blending. Applied Clay Science, Volume 50(2), pp. 255259

Zhang, Y., Zhang, Q., Liu, Q., Cheng, H., Frost, R.L., 2014. Thermal Stability of Styrene Butadiene Rubber (SBR) Composites Filled with Kaolinite/Silica Hybrid Filler. Journal of Thermal Analysis and Calorimetry, Volume 115, pp. 1013-1020 